\title{
Effect of Slenderness Ratio on Fatigue Life of CFRP Strengthened Steel I-Beam
}

\author{
Md. Shariful Islam ${ }^{a}$, Md. Abdul Hasib $b^{*}$ \\ ${ }^{a, b}$ Department of Mechanical Engineering, Khulna University of Engineering \& Technology, Khulna, \\ Bangladesh. \\ ${ }^{*}$ E-mail address: $\underline{\text { sharifulmekuet@gmail.com }}{ }^{a}, \underline{\text { ahasib } @ \text { me.kuet.ac.bd }^{b^{*}}}$
}

ORCID numbers of authors:

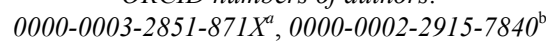

Received date: 21.07 .2020

Accepted date: 30.09 .2020

\begin{abstract}
Carbon fiber reinforced polymers (CFRP) to repair and strengthen the steel I-beam has been increasingly used since last decade. CFRP composites bonded to steel members offer many advantages over steel plate bonding including excellent corrosion resistance, high stiffness and high strength to weight ratios etc. This study numerically investigates the fatigue performance of CFRP strengthened steel I-beam. One non-strengthened control beam and several strengthened beams using steel plates and CFRP strips were investigated primarily. The effect of slenderness ratios of web on fatigue behavior of CFRP strengthened steel I-beam is investigated. The beams were simulated in full three-dimension and fatigue life was investigated by using general-purpose finite element program, ANSYS. Simply supported beam subjected to two loads on compression flange is analyzed to show the effect of CFRP and slenderness ratios on fatigue behavior of steel I beam. The results show, that the life cycle of a CFRP strengthened beam before failure is higher than that of bare beam. It is also observed that beams with higher slenderness ratios (fixed thickness of the web) give better fatigue performance.
\end{abstract}

Keywords: CFRP, I-beam, Fatigue, Slenderness ratio.

\section{Introduction}

Strengthening of steel structural member with carbon fiber reinforced polymer (CFRP) has gained much research attraction last couple of years. The structures used in bridges of railway and highway, marine industry may experience deterioration over time due to lots of reasons like environmental effects, corrosion, fatigue, high intensity loading, and gradual loss of strength with time, etc. The deterioration due to fatigue of structural member has become a major challenge faced by different infrastructure, bridge and other industries. FRP externally bonded to structures possesses many advantages such as high strength to weight ratio, high corrosion resistance or resistance to oxidation, high durability, ease of installation etc. Among different FRP, carbon fiber and glass fiber have shown more stability in strengthening structural members.

Numerous experiments have been carried out on the behavior of steel or concrete beams reinforced with CFRP plates. Conventionally steel plates are added to the bottom flange of Ibeam. In similar fashion CFRP laminates are also added to the tension flange for flexural 
strengthening. Edberg et al. carried out experimental investigations on some different configurations of strengthened beam, with CFRP and GFRP. The results obtained in both cases were observed, and it found that CFRP laminated beams show more strength than GFRP laminated beams. In other words, CFRP strengthening is more effective than GFRP strengthening [1]. Tavakkolizadeh et al. also investigated the fatigue performance of CFRP strengthened steel girders [2]. They showed that CFRP strengthened beam has much higher life than with strengthening, in fact, they found three times life in CFRP strengthened beam. Also, crack growth rates are decreased significantly. Dawood et al investigated the primary behavior of scaled bridge beams of steel-concrete combination strengthened with HM CFRP materials [3]. They compared their results with analytical models based on the fundamental principles of equilibrium and compatibility. Fernando et al conducted several studies on the fatigue strengthening of steel beams using fiber reinforced polymer and they showed the overall performance of beam strengthened with CFRP [4]. They also investigated the fatigue behavior of cracked steel beams with externally bonded CFRP laminates. Kim et al investigated fatigue behavior of intentionally created notched beam strengthened with CFRP in Finite element method and predicted the fatigue life based on strain life theory [5]. Finally, they propose an empirical model to predict fatigue behavior of the interface. Xie et al investigated the fatigue behavior of CFRP strengthened beam equipped with three-point bending [6]. An empirical formula was developed to predict the fatigue life of CFRP strengthened beam based on experimental observation. Colombi et al performed fatigues tests on cracked steel plates strengthened on one side and evaluated fatigue crack propagation curves by integrating paris law and finally compared this with experimental data [7]. Wang et al investigated experimentally the fatigue behavior of bonded surface between steel plates and carbon fiber reinforced polymer laminate [8]. It is observed that fatigue life is very much responsive to adhesive thickness and fatigue life increases with increase in adhesive thickness. El-Emam et al used ultra-high modulus (UHM) CFRP laminates to enhance the fatigue life of pre-cracked steel beams [9]. They found positive results in UHM carbon fiber reinforced polymer and the life is much increased with UHM CFRP. Effects of significant parameters like the slenderness ratio of web of I-beam on fatigue performance are yet to be analyzed.

In this paper fatigue performance of CFRP strengthened steel I-beams is observed. The effect of the slenderness ratio of web of CFRP strengthened I-beam is investigated.

\section{Materials and Methods}

\subsection{Materials}

In this analysis, steel I-beam of grade ASTM(A36) is strengthened by CFRP strip and steel plate as well to investigate the fatigue performance of CFRP. Table 1 shows material properties of the I-beams. Fig. 1 indicates the dimensions of the steel I-section. The steel plates used for flexural reinforcement and stiffener are of the same grade as the steel I-beams. Steel plate $\mathrm{A}$ is installed on the bottom flange by using adhesive (Sikadur-30). The dimensions of the steel plates, CFRP and adhesive are shown in table 2. CFRP materials have high tensile strength which can improve the structural behavior of structures. Normally, CFRP

Table 1: Mechanical properties of structural steel [10].

\begin{tabular}{cccc}
\hline \multirow{2}{*}{$\begin{array}{c}\text { Young's Modulus } \\
(\mathrm{MPa})\end{array}$} & Poisson's Ratio & $\begin{array}{c}\text { Yield Strength } \\
(\mathrm{MPa})\end{array}$ & $\begin{array}{c}\text { Tangent Modulus } \\
(\mathrm{MPa})\end{array}$ \\
\hline 210000 & 0.3 & 250 & 1450 \\
\hline
\end{tabular}




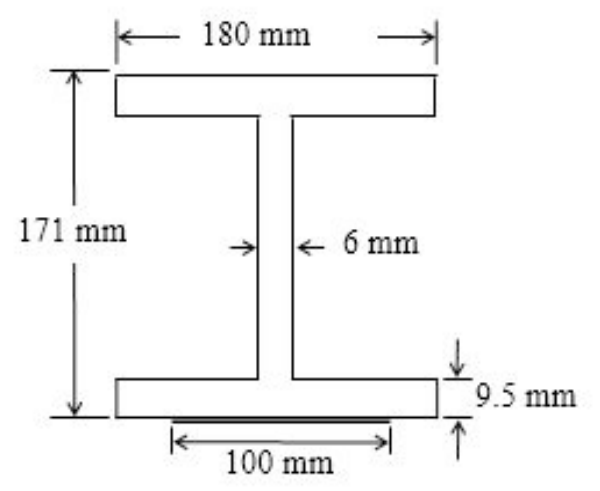

Fig.1. Dimensions of steel I-Section.

Table 2: Dimensions of steel plate, CFRP and adhesive.

\begin{tabular}{rccc}
\hline & Width $(\mathrm{mm})$ & Length $(\mathrm{mm})$ & Thickness $(\mathrm{mm})$ \\
\hline Plate A & 100 & 1500 & 6,8 \\
CFRP & 100 & 1500 & 1.2 \\
Adhesive & 100 & 1500 & 1 \\
\hline
\end{tabular}

Table 3: Properties of CFRP $[11,12]$.

\begin{tabular}{ll}
\hline & Parameter \\
\hline Young's modulus in $X$ direction $(\mathrm{MPa})$ & 310000 \\
Young's modulus in $Y$ direction $(\mathrm{MPa})$ & 11200 \\
Young's modulus in $Z$ direction $(\mathrm{MPa})$ & 11200 \\
Poisson's Ratio $X Y$ & 0.0058 \\
Poisson's Ratio $Y Z$ & 0.3 \\
Poisson's Ratio $X Z$ & 0.0058 \\
Shear Modulus $X Y(\mathrm{MPa})$ & 26500 \\
Shear Modulus $Y Z(\mathrm{MPa})$ & 3700 \\
Shear Modulus $X Z(\mathrm{MPa})$ & 26500 \\
Tensile strength $(\mathrm{MPa})$ & 3100 \\
\hline
\end{tabular}

is produced in the form of a strip (plate) or a sheet (wrap). In this study, CFRP strip is installed on the tensile region to improve the fatigue performance of structures. Table 3 shows material properties of the CFRP, which is orthotropic in behavior

\subsection{Finite Element Model}

This analysis is performed by the general-purpose finite element program, Ansys v18.1. All the parts, including I section, CFRP, steel plate and adhesive, in the Finite element analysis, were modelled using higher order 3D 20 nodes solid elements, SOLID186. The beam is supported with simply supported condition as shown in fig 3 . There are two supports at two ends, one is pin support another is roller support. In pin support displacements in the $\mathrm{x}, \mathrm{y}$ and $\mathrm{z}$ direction is restricted but moments in these directions are not restricted i.e. free to rotate. On the other hand, in roller support displacement in y direction is restricted but there are five 

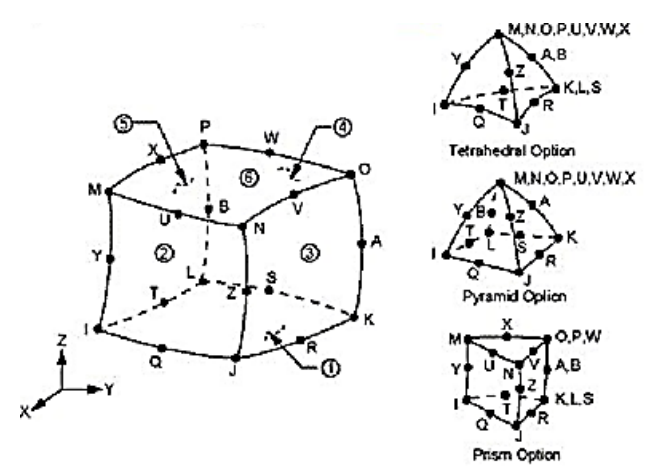

Fig. 2. Solid 186 element type in Ansys [13].

degrees of freedom this support. Two loads of equal magnitude are applied at the top of the compression flange along lines. The beam's free span is $1.8 \mathrm{~m}$ and the length of the CFRP sheets adhered to the tension flange is $1.5 \mathrm{~m}$. The free length between the end of the CFRP and the supports is not strengthened. For fatigue life estimation S-N curve is used and S-N curve for steel and CFRP are shown in fig. 4.

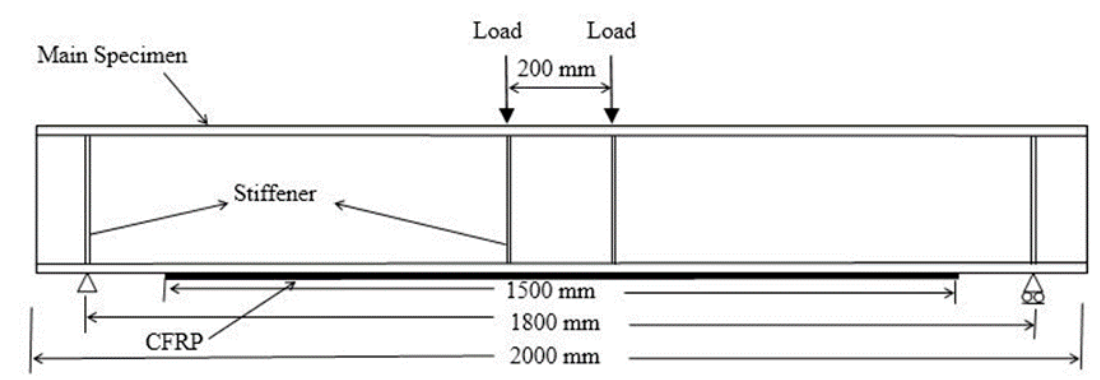

Fig. 3. Specifications of the strengthened steel I-beam.

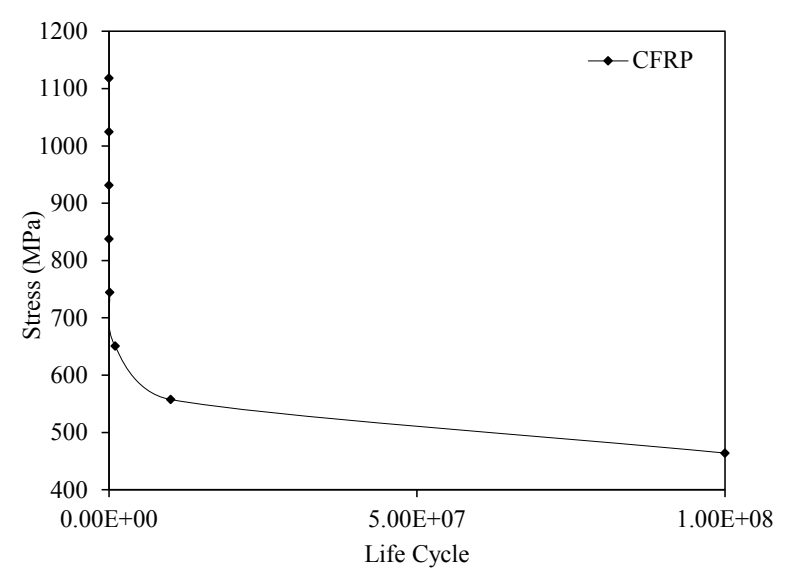

(a)

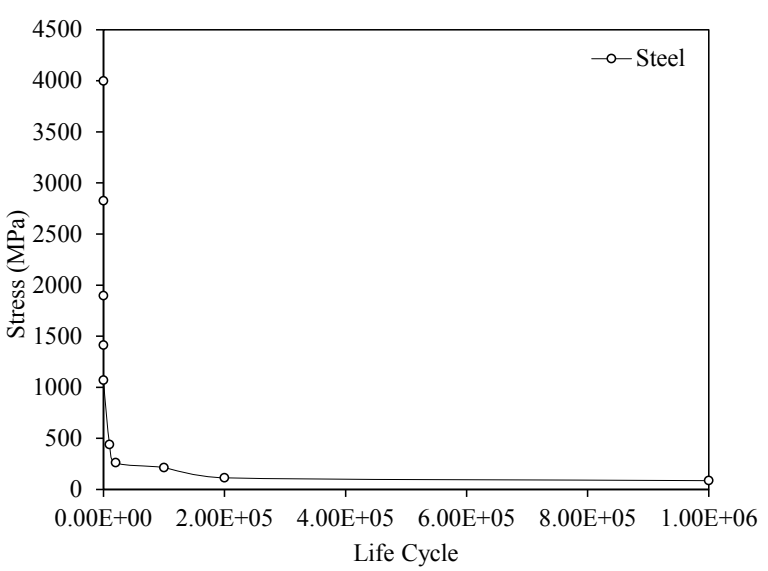

(b)

Fig. 4. S-N curve for (a) CFRP [13] and (b) Steel [14]

\subsection{Model Validation}

The model is investigated by using a general-purpose finite element program, ANSYS. To validate the present model, the specimen was equipped and material properties were taken as of reference specimen from literature. The load-deflection curve at midspan of the without strengthening beam is compared with the experimental result as shows in fig. 5(a). It is observed that the present study maintains a very good agreement with the reference beam from literature. 


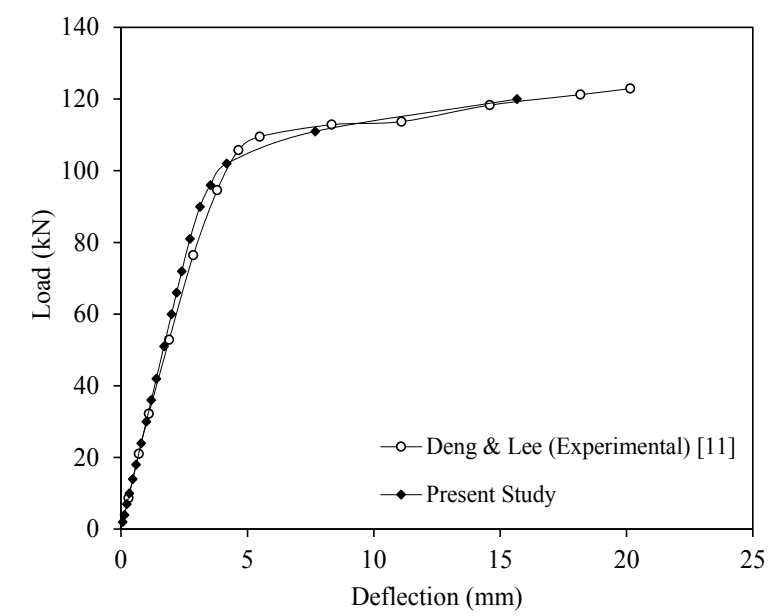

(a)

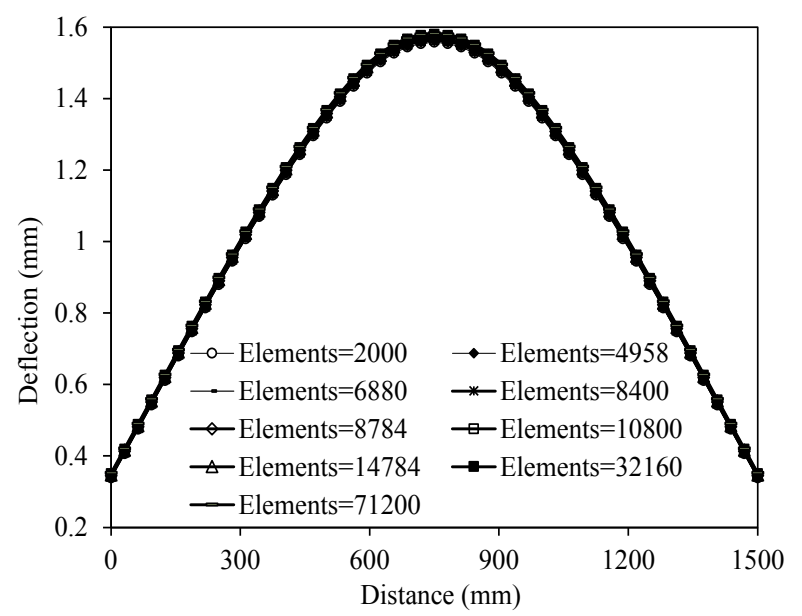

(b)

Fig. 5. (a) Load-deflection curves for previous study and present study, (b) Deflection along the length of CFRP for different element counts.

\subsection{Mesh Independence Test}

To obtain independent mesh for the further analysis a result is compared to different meshing combination. In this case deflections along the length of the beam for a specific loading condition for different elements are shown in fig. 5(b). It is found that for different elements and nodes the change in deflection is very little or negligible. That indicates independence of the model. Finally, a model with elements of 32160 was selected for further analysis.

\section{Results and Discussions}

\subsection{Effect of CFRP on Fatigue Life}

In order to show the effect of CFRP on life expectancy the fatigue life for bare beam, steel plate strengthened beams and CFRP strengthened beam are compared as shown in fig. 6 . It is obvious from figure that the minimum life, at which any part of the beam will fail before design life is reached for CFRP strengthened beam is much higher than that of the bare beam and steel plate strengthened beams.

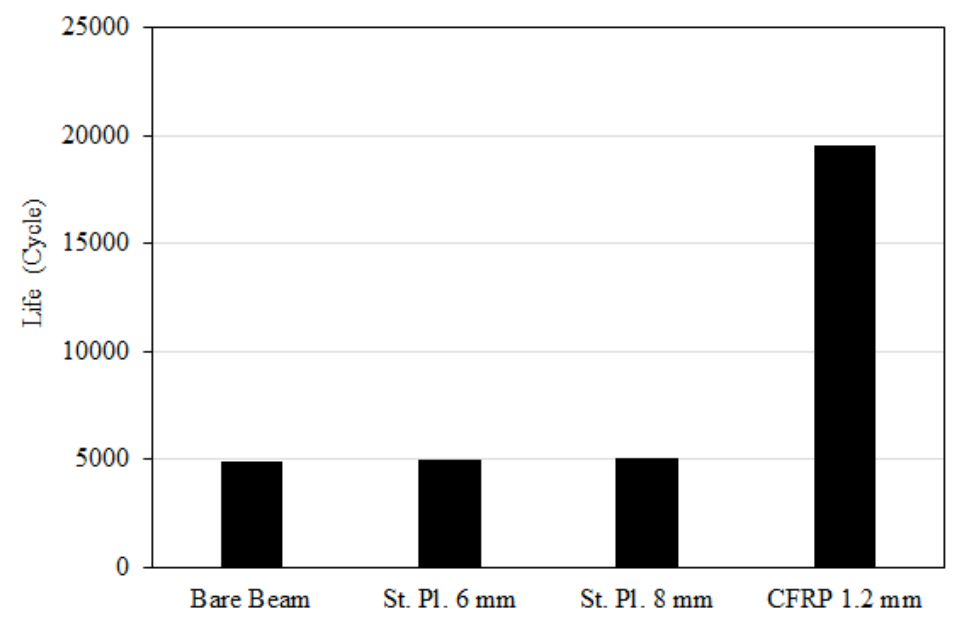

Fig. 6. Estimated life for the load of $100 \mathrm{kN}$ for bare beam and strengthened beams. 


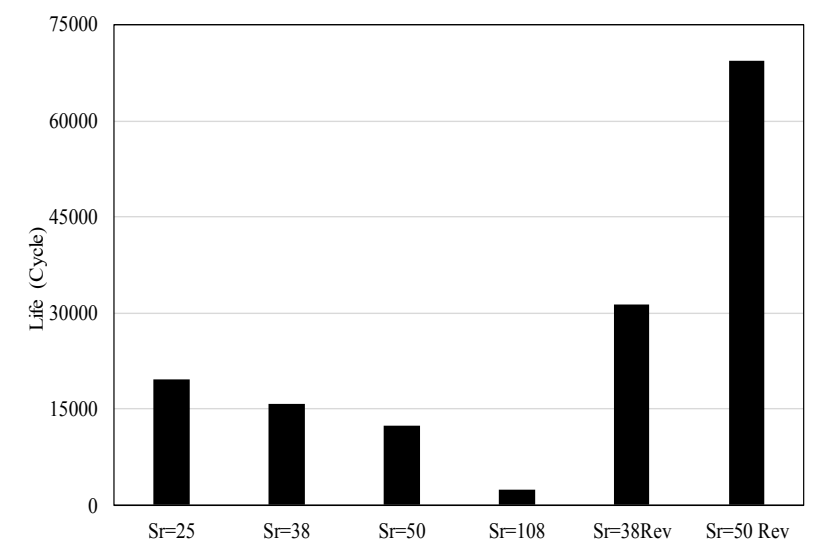

(a)

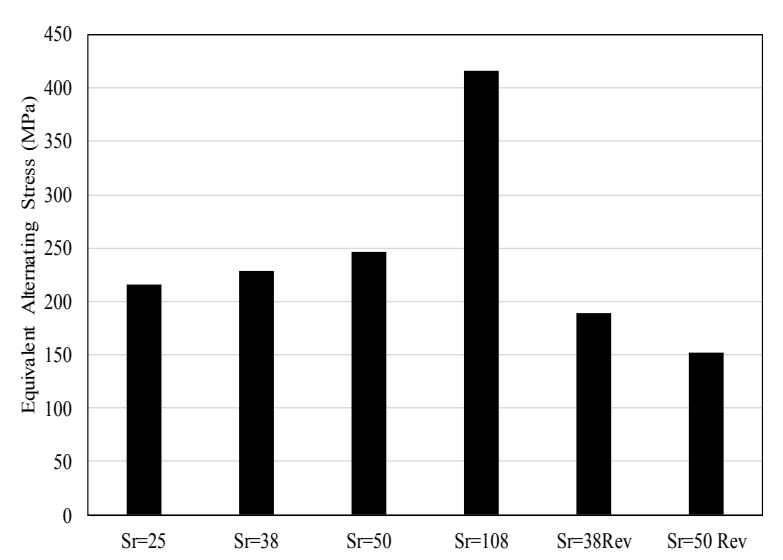

(b)

Fig. 7. (a) Estimated life, and (b) Equivalent alternating stress for the load of $100 \mathrm{kN}$ for different Slenderness ratios

\subsection{Fatigue life and Equivalent Alternating Stress}

Fig. 7(a) depicts the fatigue life for different slenderness ratio ranging from 25 to 108 . With the increase in slenderness ratios with a fixed height of the web, life cycle of the beam before failure decreases. But, when slenderness ratio is increased with a fixed width of the web, then life cycle of the beam increases. Fig. 7(b) shows the equivalent alternating stresses for different slenderness ratios. It is observed that with the increase in the slenderness ratio from 25 to 108 with varying width of the web, the equivalent alternating stress increases, but when slenderness ratio is increased with varying height of the beam, equivalent alternating stress decreases.

\subsection{Fatigue Sensitivity}

Fatigue sensitivity analysis shows, how fatigue life will respond with change of load at a certain range. In this analysis, fatigue sensitivity analysis is done in the range of $50 \%$ of load to $150 \%$ of load. Fatigue sensitivity analysis is performed for different slenderness ratios. With the increase in the slenderness ratio keeping the height of the web fixed, the life cycle is

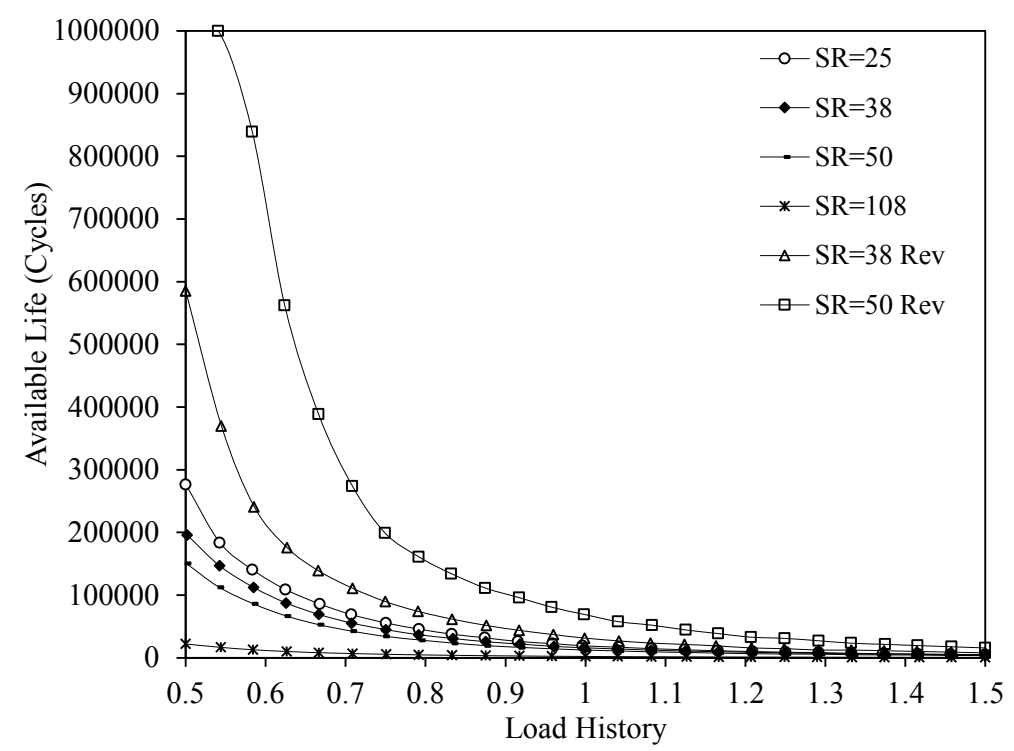

Fig. 8. Comparison of fatigue sensitivity for $100 \mathrm{kN}$ load among slenderness ratios. 
decreased for all loading condition. At the same time, while the slenderness ratio is increased keeping fixed the width of the web, life cycle is increased. Fig. 8 depicts available life cycle for different slenderness ratios, where 1 indicates the original loading $(100 \mathrm{kN})$ and 1.5 indicates $150 \mathrm{kN}$ and so on.

\section{Conclusions}

In this study fatigue performance of steel I-beam strengthened with carbon fiber reinforced polymer (CFRP) is analyzed numerically. CFRP laminates and steel plates are added to the bottom of the steel I beam to strengthen the member. One bare beam along with strengthened beams using CFRP laminates and steel plates are investigated. Specific outcomes of this investigation are-

o Life cycle that a beam can sustain under fatigue loading, before failure for CFRP strengthened is higher than that of bare beam.

o Beams with higher slenderness ratios (fixed thickness of the web) give better fatigue performance.

\section{References}

[1] Edberg, W., Mertz, D., Gillespie, J., Rehabilitation of steel beams using composite materials. ASCE fourth materials engineering conference, Washington D.C., United States, 1996.

[2] Tavakkolizadeh, M., Saadatmanesh, H.S., Fatigue strength of steel girders reinforced with carbon Fibre reinforced polymer patch. Journal of Structural Engineering, 129, 186-196. 2003.

[3] Dawood, M., Rizkalla, S., Sumner, E., Fatigue and Overloading Behavior of SteelConcrete Composite Flexural Members Strengthened with High Modulus CFRP Materials. Journal of Composites for Construction, 11, 659-669, 2007.

[4] Fernando, D., Schumacher, A., Motavalli, M. fatigue strengthening of cracked steel beams with cfrp plates. Proceedings of the ASME 2010 International Mechanical Engineering Congress \& Exposition, Vancouver, British Columbia, Canada, 2010.

[5] Kim, Y.J., Harries, K.A., Fatigue behavior of damaged steel beams repaired with CFRP strips. Engineering Structures, 33, 1491-1502, 2011.

[6] Xie, J.h., Xin, P.Y.H., Guo, X.Y., Fatigue behavior of reinforced concrete beams strengthened with prestressed fibre reinforced polymer. Construction and Building Materials, 27, 149-157, 2012.

[7] Colombia, P., Favaa, G., Poggia, C., Fatigue reinforcement of steel elements by CFRP materials: experimental evidence, analytical model and numerical simulation. Procedia Engineering, 74, 384-387, 2014.

[8] Wang, H.T., Wu, G., Pang, Y.Y., Experimental study on the bond behavior between CFRP plates and steel substrates under fatigue loading. Composites Part B: Engineering, 176, 1-12, 2019. 
[9]. El-Emam, H., Mustafic, M., Salim,H., Elsisi, A., Sallam, H., Fatigue Life Enhancement for Steel Girders Using Ultra-High Modulus Carbon Fiber-Reinforced Polymer, ASCE Structures Congress, Reston, United States, 2019.

[10] ASTM A36 Steel Properties, Modulus of Elasticity, Yield Strength, Material Density, Hardness \& Equivalent, US ASTM AISI and Save Standards, World Material.

[11] Deng, J., Jun Deng, Lee, M.M.K, Moy, S.S.j., Stress analysis of steel beams reinforced with a bonded CFRP plate. Composite Structures, 65, 205-215, 2004.

[12] SIKA® Product Information, S.e., Sika® Kimia Sdn Bhd., Kuala Lumpur.

[13] Zaharia, S.M., Morariu, C.O., Nedelcu, A., Pop, M.A., Experimental Study of Static and Fatigue Behavior of CFRP-Balsa Sandwiches under Three-point Flexural Loading, Bio Resources, 12, 2673-2689, 2017.

[14] Library, Ansys Workbench Module. 